\title{
Spillover of Peste des Petits Ruminants Virus from Domestic to Wild Ruminants in the Serengeti Ecosystem, Tanzania
}

\author{
Mana Mahapatra, Kuya Sayalel, Murali Muniraju, \\ Ernest Eblate, Robert Fyumagwa, Ligge Shilinde, \\ Maulid Mdaki, Julius Keyyu, Satya Parida, ${ }^{1}$ \\ Richard Kock ${ }^{1}$
}

We tested wildlife inhabiting areas near domestic livestock, pastures, and water sources in the Ngorongoro district in the Serengeti ecosystem of northern Tanzania and found $63 \%$ seropositivity for peste des petits ruminants virus. Sequencing of the viral genome from sick sheep in the area confirmed lineage II virus circulation.

$\mathrm{P}$ este des petits ruminants (PPR) is caused by peste des petits ruminants virus (PPRV), a member of the genus Morbillivirus in the family Paramyxoviridae, and primarily affects sheep and goats. Although PPRV can infect a wide range of domestic and nondomestic species, the disease has not been confirmed in free-ranging wildlife species in sub-Saharan Africa. Increased understanding of the epidemiology of PPRV infection in mixed species environments is urgently needed, especially because the virus range has apparently expanded in recent years, with associated social and economic effects of epidemics in areas where the disease had not been circulating, including programs for ongoing control (1).

PPR was first reported in northern Tanzania in 2008 and resulted from a southward spread from Kenya and Uganda by migrating livestock $(2,3)$. No serologic and clinical reports of PPRV infection in wildlife occurred in subSaharan Africa during 2005-2013, although seropositivity was recorded in Uganda, Ethiopia, and other countries in West and Central Africa before this period (4). A study of serum samples collected from 331 wildlife 1-12 years of age in Tanzania, including in the Serengeti, Arusha, Katavi, and Tarangire National Parks and in the Ngorongoro Crater in the Ngorongoro Conservation Area (NCA), showed seronegative results for PPRV (5); however, that

Author affiliations: The Pirbright Institute, Woking, UK

(M. Mahapatra, M. Muniraju, S. Parida); Ngorongoro Conservation Area Authority, Arusha, Tanzania (K. Sayalel); Tanzania Wildlife

Research Institute, Arusha (E. Eblate, R. Fyumagwa, S. Shilinde,

M. MaulidMdaki, J. Keyyu); University of London, London, UK

(R. Kock)

DOI: http://dx.doi.org/10.3201/eid2112.150223 study did not include animals from our study area. Another study of $>500$ serum samples from wildlife in northeastern Kenya, tested during 2008-2010 for the Somali Ecosystem Rinderpest Eradication Coordination Unit program, also showed seronegative results for PPRV (F. Gakuya, pers. comm., 2012). In both studies, samples taken in Kenya and Tanzania were banked samples collected opportunistically during other research activities in the study areas. These results indicated that wildlife were not being infected by PPRV in this region; however, because of the opportunistic sampling, more targeted surveillance was considered necessary to confirm this PPRV-seronegative status (5). Given the proposed global eradication of PPRV by 2030 (6), we sought to determine the role of wildlife as possible hosts and sentinels of PPRV infection in northern Tanzania.

\section{The Study}

In June 2014, we investigated whether evidence could be found for PPRV infection in resident wildlife as a result of possible spillover from domestic animals (i.e., nomadic pastoral and agropastoral livestock), with whom they may share pasture and water resources in the Ngorongoro district within NCA (Figure 1). After obtaining ethical approval through the Animal Health and Welfare European Research Area Network; the Biotechnology and Biological Sciences Research Council; and Tanzania government departments responsible for research on wildlife and livestock, we collected serum samples from wildlife near resident livestock or from pastures and water sources shared with resident and nomadic livestock. Sampling was performed during the dry season, so only resident wildlife were sampled; migratory populations had already moved northwest from NCA. Both netting and chemical immobilization were used in 11 sampling sites, and samples were collected from 46 wild animals (Table 1). After the animals were restrained, they were clinically examined, and age was determined on the basis of incisor tooth eruption. Whole blood samples were collected with and without anticoagulant, and eye and nasal swabs were taken.

Similar sets of blood, eye, and nasal samples were collected from 5 domestic sheep and 5 goats that were reportedly ill with suspected signs of PPR ( 2 herds) or opportunistically sampled (1 herd) in locations across the wildlife range, which included 1 resident livestock herd

${ }^{1}$ These authors contributed equally to this article. 


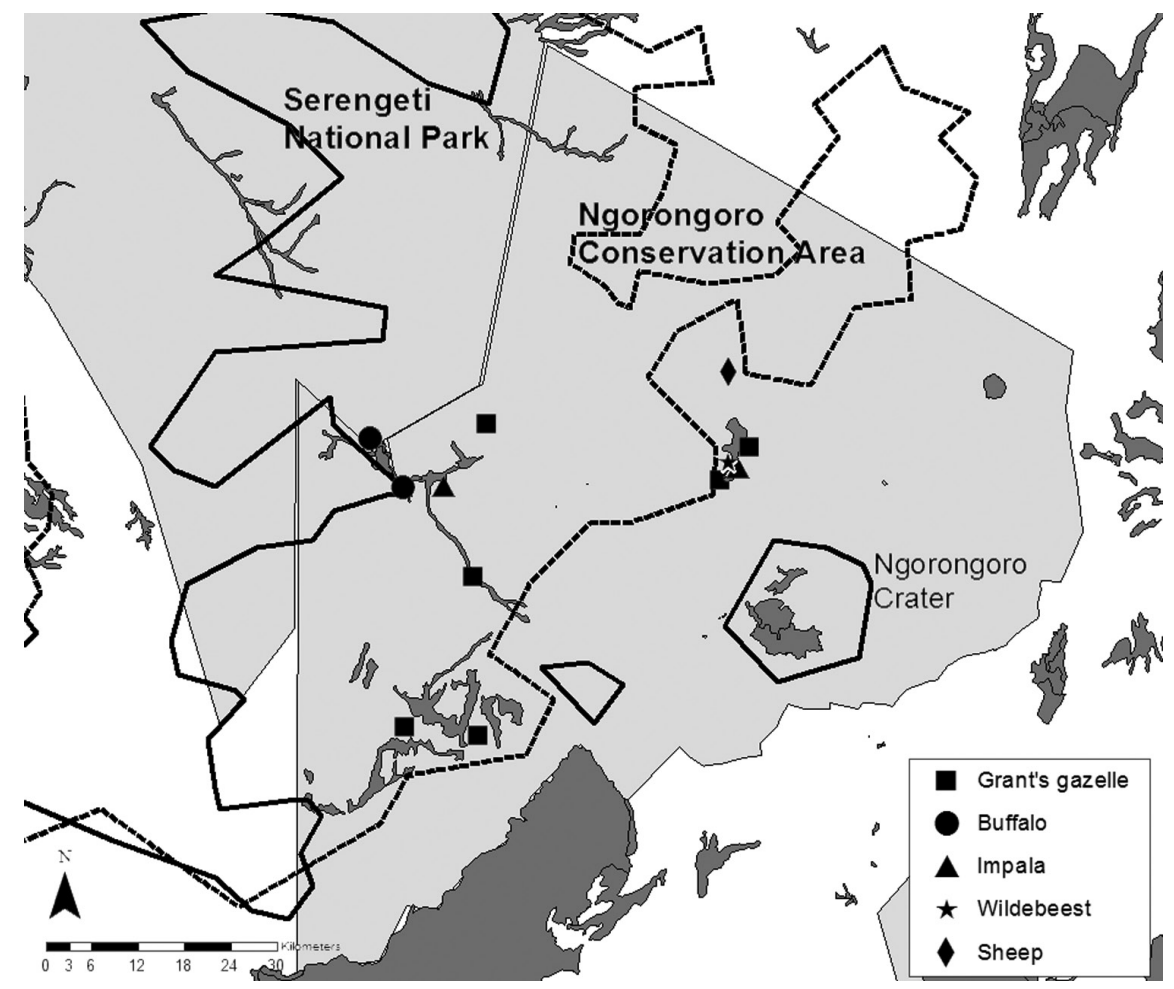

Figure 1. Geospatial map of sampling area showing distribution of buffalo (2014) and nonbuffalo (2006) species in the Greater Serengeti Ecosystem, northern Tanzania. Map is constructed on the basis of aerial census data and sites of livestock and wildlife herds sampled in June 2014 and found to be positive for peste des petits ruminants virus (PPRV) infection in the Ngorongoro Conservation Area.

in a high-altitude location and 2 nomadic livestock herds in low-altitude locations. No positive results were obtained from small livestock sampled in the highlands of Ngorongoro Crater. Three sheep (1 young, 1 semi-adult, and 1 adult) from the Esieki plains in the northern part of NCA were fresh cases with PPRV-specific clinical signs; their eye and nasal swab samples tested positive for PPRV antigen by a lateral flow device (7) (Table 2; online Technical Appendix Figure 1, http://wwwnc.cdc.gov/ EID/article/21/12/15-0223-Techapp1.pdf). Although the adult animals had been vaccinated in April 2013, lambs $<4$ months of age and those born after that month were unvaccinated, creating a window for PPRV infection in the vaccinated herd and indicating a vital need to vaccinate all kids and lambs immediately after weaning, when they lose protection by maternal antibodies.

Real-time reverse transcription PCR (9) confirmed PPRV infection in all 3 PPRV-positive sheep from the Esieki plains. In addition, a sample from 1 Grant's gazelle in the Esieki plains was also positive (cycle threshold 34).
Samples from 2 domestic young goats from Ngoile, NCA, were also positive (cycle threshold 32 and 37). Amplification of the PPR genome in gel-based PCR was possible only from swabs from the 3 clinically positive animals by using N-gene primers (10). The partial N-gene sequences available in GenBank for Africa through December 2014 were aligned and used for constructing a neighborhoodjoining phylogenetic tree (Figure 2) that confirmed co-circulation of lineage II PPRV along with lineage III and IV in Tanzania (11-14). Recently, lineage II has been circulating in Central Africa $(12,13)$. Possible incursion of lineage II from Central to East Africa, particularly to Tanzania, may have been overlooked because not all outbreaks are reported or investigated by viral genome sequencing.

In addition to infection among domestic livestock, detection of antibodies in blood samples by H c-ELISA (Biological Diagnostic Supplies Ltd., Ayrshire, UK) (8) showed PPRV seropositivity in all wildlife species and herds sampled across NCA except for Thomson's gazelle, but only 1 animal of this species was sampled (Table 1). Age-specific

\begin{tabular}{lccccc}
\hline \multicolumn{5}{l}{ Table 1. Seroprevalence of peste des petits ruminants virus in wildlife in the Ngorongoro Conservation Area, Tanzania, 2014 } \\
\hline Species & $\begin{array}{c}\text { No. } \\
\text { sampled }\end{array}$ & $\begin{array}{c}\text { No. positive/no. } \\
\text { negative }\end{array}$ & $\begin{array}{c}\text { Individual } \\
\text { prevalence, } \%\end{array}$ & $\begin{array}{c}\text { No. herds } \\
\text { sampled }\end{array}$ & $\begin{array}{c}\text { No. positive/no. } \\
\text { negative }\end{array}$ \\
prevalence, \%
\end{tabular}


Table 2. Seroprevalence of peste des petits ruminants virus in domestic small ruminants in the Ngorongoro Conservation Area, Tanzania, 2014

\begin{tabular}{lccc}
\hline & & \multicolumn{2}{l}{ No. positive/no. negative } \\
\cline { 3 - 4 } Species & No. sampled & H c-ELISA* & LFD antigen test† \\
\hline Goat & 5 & $2 / 0$ & $0 / 5$ \\
Sheep & 5 & $0 / 2$ & $3 / 2$ \\
Total & 10 & $2 / 2$ & $3 / 7$ \\
\hline *Serum samples from 2 animals from each species were used to detect \\
antibodies by H c-ELISA (8). \\
†Eye and nasal swab samples from 5 animals from each species were \\
used for antigen testing with a lateral flow device (LFD) (7). \\
\hline
\end{tabular}

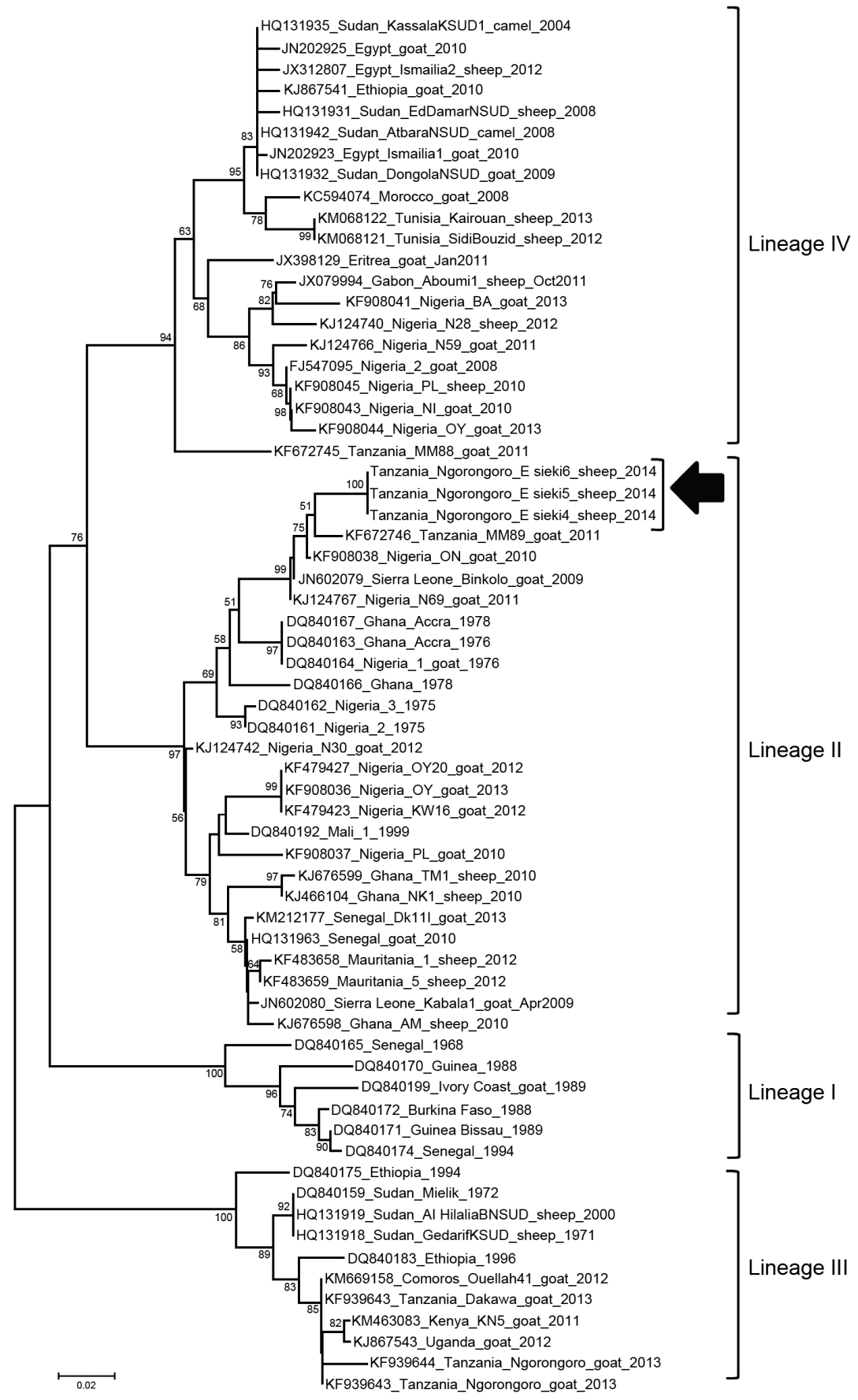

data for the buffalo and Grant's gazelle showed seropositivity increasing with age (online Technical Appendix Figure 2 , panels $\mathrm{A}$ and $\mathrm{B}$ ) and included animals $<6$ months of age.

\section{Conclusions}

Our findings provide evidence for PPRV infection in wildlife in East Africa. Recurring outbreaks in NCA in Tanzania confirm that PPRV, having recently emerged in this region, is likely now endemic in this area and is circulating

Figure 2. Neighbor-joining tree constructed on the basis of partial $\mathrm{N}$-gene sequences of peste des petits ruminants virus (PPRV), showing relationships among the PPRV isolates from Africa. The Kimura 2-parameter model was used to calculate percentages (indicated by numbers beside branches) of replicate trees in which the associated taxa clustered together in 1,000 bootstrap replicates. Arrow indicates isolates sequenced in this study; sequences have been submitted to GenBank and are awaiting accession numbers. Scale bar indicates nucleotide substitutions per site. 
among sheep, goats, and wildlife despite several rounds of mass vaccination. Most wild ruminant species and sampled subpopulations or herds sharing range with small livestock in NCA have been infected with PPRV, with the youngest wild animal confirmed antibody positive at $\approx 6$ months of age, suggesting recent exposure.

Our sample represents resident wildlife in NCA and not migrating populations in the ecosystem. The positive result from a small resident herd of wildebeest near Olbalbal warrants closer examination of the PPRV status of migrating populations of wildebeest, Thomson's gazelle, and topi (a type of antelope, Damaliscus lunatus), which moved out of the area during April-May 2014. The single Thomson's gazelle sample is inconclusive. Age-specific data show that antibody prevalence rises with age, suggesting intermittent but regular exposure in the wildlife populations; however, circulation of the virus within and between the populations of each wildlife species is also possible.

The transmission and spread of PPRV appears to be considerable; high seroprevalence is observed at individual and herd levels, without all animals being infected, suggesting lower infective loads in the wildlife and a possibility that most infections could result from direct spillover of virus from infected livestock. The possibility of spillover infections is supported by the apparent absence of antibodies in the wildlife populations that have no contact with livestock (5).

Absence of clinical evidence in wildlife does not constitute evidence of absence of the disease. Antibodies were present in many wildlife we sampled, and the genome was present in 1 Grant's gazelle in the Esieki plains, where ongoing outbreaks were confirmed in domestic sheep. Clinical infections caused by PPRV have been recorded often in captive gazelle (Gazella species) (15) in United Arab Emirates. Currently, no evidence of wildlife disease exists, but cases or carcasses might go unnoticed because of deaths from other causes and rapid removal of dead animals by scavengers. These findings confirm endemic PPRV in the Greater Serengeti Ecosystem and suggest that free-ranging wildlife are susceptible to infection and can act as sentinels of livestock disease but do not appear to be maintaining infection across their populations.

\section{Acknowledgments}

We thank the Ministry of Livestock and Fisheries Development; Tanzania Wildlife Research Institute; Ngorongoro Conservation Area Authority; and the Tanzania Commission for Science and Technology for permissions and assistance with field activities.

We also thank the Biotechnology and Biological Sciences Research Council and the European Commission Animal Health and Welfare European Research Area Network fund for providing support for epidemiologic research under the Improved
Understanding of the Epidemiology of Peste-des-Petits Ruminants project led by The Pirbright Institute (BB/L013657/1) and the Royal Veterinary College (BB/L013592/1).

Dr. Mahapatra is trained as a veterinarian, has a doctoral degree in molecular virology, and currently works as a senior scientist at the Pirbright Institute, UK. Her research interests include the epidemiology of peste des petits ruminants disease and the development of a DIVA vaccine that can be used in eradication of this disease.

\section{References}

1. Banyard AC, Parida S, Batten C, Oura C, Kwiatek O, Libeau G. Global distribution of peste des petits ruminants virus and prospects for improved diagnosis and control. J Gen Virol. 2010;91:2885-97. http://dx.doi.org/10.1099/vir.0.025841-0

2. Karimuribo ED, Loomu PM, Mellau LSB, Swai ES. Retrospective study on sero-epidemiology of peste des petits ruminants before its official confirmation in northern Tanzania in 2008. Research Opinions in Animal and Veterinary Sciences. 2011;1:184-7.

3. Swai ES, Kapaga A, Kivaria F, Tinuga D, Joshua G, Sanka P. Prevalence and distribution of Peste des petits ruminants virus antibodies in various districts of Tanzania. Vet Res Commun. 2009;33:927-36. http://dx.doi.org/10.1007/s11259-009-9311-7

4. Kock RA. Rinderpest and wildlife. In: Barrett T, Pastoret P-P, Taylor WP, editors. Rinderpest and peste des petits ruminants virus. Plagues of large and small ruminants. London: Academic Press; 2006. p. 144-62.

5. Lembo T, Oura C, Parida S, Hoare R, Frost L, Fyumagwa R, et al. Infection among cattle and wildlife in northern Tanzania. Emerg Infect Dis. 2013;19:2037-40. http://dx.doi.org/10.3201/ eid1912.130973

6. Baron MD, Parida S, Oura CA. Peste des petits ruminants: a suitable candidate for eradication? Vet Rec. 2011;169:16-21. http://dx.doi.org/10.1136/vr.d3947

7. Baron J, Fishbourne E, Couacy-Hyman E, Abubakar M, Jones BA, Frost L, et al. Development and testing of a field diagnostic assay for peste des petits ruminants virus. Transbound Emerg Dis. 2014;61:390-6. http://dx.doi.org/10.1111/ tbed.12266

8. Anderson J, McKay JA. The detection of antibodies against peste des petits ruminants virus in cattle, sheep and goats and the possible implications to rinderpest control programmes. Epidemiol Infect. 1994;112:225-31. http://dx.doi.org/10.1017/ S0950268800057599

9. Batten CA, Banyard AC, King DP, Henstock MR, Edwards L, Sanders A, et al. A real time RT-PCR assay for the specific detection of peste des petits ruminants virus. J Virol Methods. 2011;171:401-4. http://dx.doi.org/10.1016/ j.jviromet.2010.11.022

10. Couacy-Hymann E, Roger F, Hurard C, Guillou JP, Libeau G, Diallo A. Rapid and sensitive detection of peste des petits ruminants virus by a polymerase chain reaction assay. J Virol Methods. 2002;100:17-25. http://dx.doi.org/10.1016/ S0166-0934(01)00386-X

11. Kgotlele T, Macha ES, Kasanga CJ, Kusiluka LJM, Karimuribo ED, Van Doorsselaere J, et al. Partial genetic characterization of peste des petits ruminants virus from goats in northern and eastern Tanzania. Transbound Emerg Dis. 2014;61:56-62. http://dx.doi.org/ 10.1111/tbed.12229

12. Muniraju M, Mahapatra M, Ayelet G, Babu A, Olivier G, Munir M, et al. Emergence of Lineage IV peste des petits ruminants virus in 
Ethiopia: complete genome sequence of an Ethiopian isolate 2010. Transbound Emerg Dis. Epub 2014. http://dx.doi.org/10.1111/ tbed. 12287

13. Libeau G, Diallo A, Parida S. Evolutionary genetics underlying the spread of peste des petits ruminants virus. Animal Frontiers. 2014;4:14-20.

14. Misinzo G, Kgotlele T, Muse EA, Doorsselaere JV, Berg M, Munir M. Peste des petits ruminants virus lineage II and IV From goats in southern Tanzania during an outbreak in 2011. British Journal of Virology. 2015;2:1-4.
15. Kinne J, Kreutzer R, Kreutzer M, Wernery U, Wohlsein P. Peste des petits ruminants in Arabian wildlife. Epidemiol Infect. 2010;138:1211-4. http://dx.doi.org/10.1017/S0950268809991592

Address for correspondence: Satya Parida, The Pirbright Institute, Ash Road, Pirbright, Woking GU24 0NF, UK; email: satya.parida@pirbright. ac.uk; Richard Kock, Royal Veterinary College, University of London, Hawkshead Lane, North Mymms Hatfield, London, AL9 7TA, UK; email: rkock@rvc.ac.uk

\section{May 2015: Vectorborne Infections Including:}

- Transmission of Hepatitis C Virus among Prisoners, Australia, 2005-2012

- Recent US Case of Variant Creutzfeldt-Jakob Disease-Global Implications

- Novel Thogotovirus Associated with Febrile Illness and Death, United States, 2014

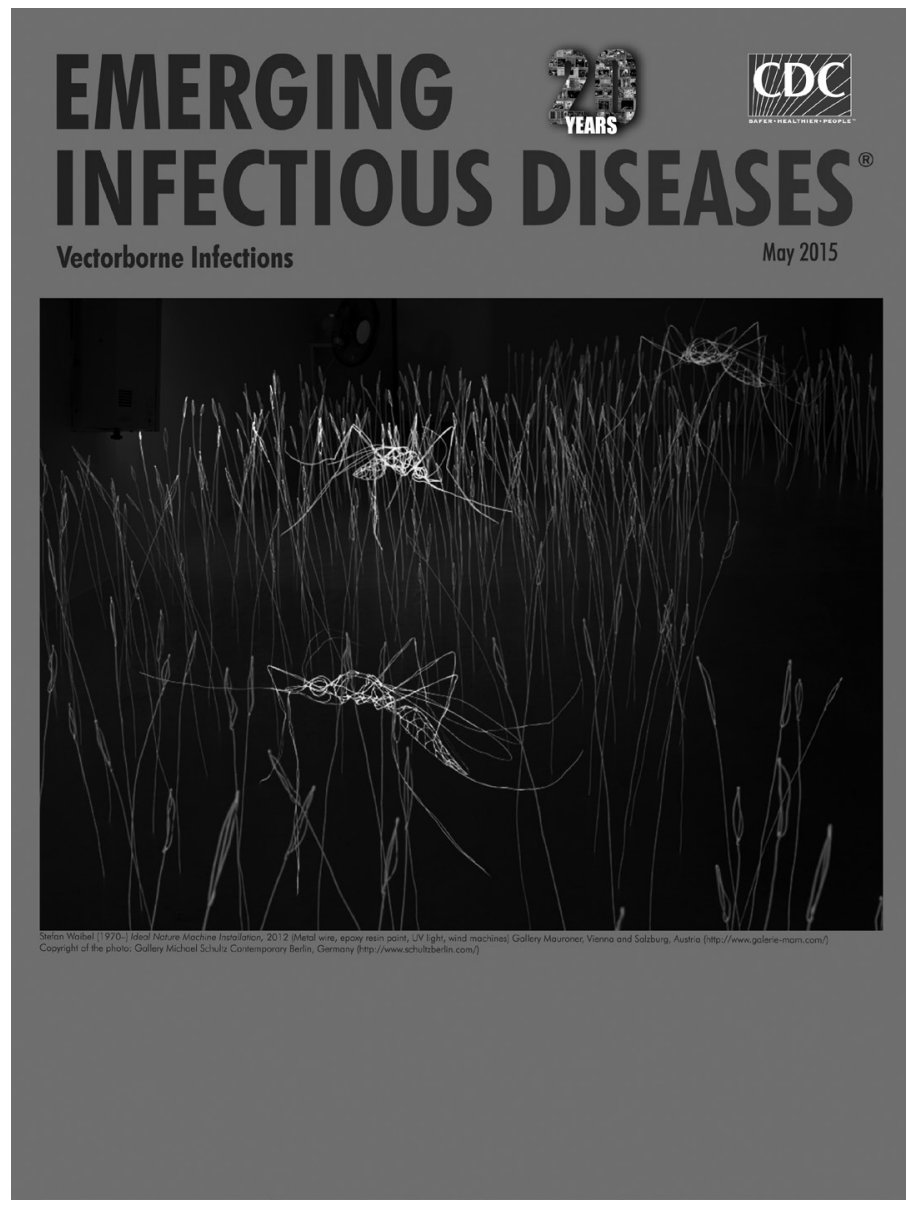

- $\mathrm{A}(\mathrm{H} 7 \mathrm{~N} 9)$ Virus Beyond China

- Pathologic Changes in Wild Birds Infected with Highly Pathogenic Avian Influenza (H5N8) Viruses, South Korea, 2014

- Itaya virus, a Novel Orthobunyavirus Associated with Human Febrile Illness, Peru

- Isolation of Onchocerca lupi in Dogs and Black Flies, California, USA

- Molecular Epidemiology of Plasmodium falciparum Malaria Outbreak, Tumbes, Peru, 2010-2012

- Delayed-Onset Hemolytic Anemia in Patients with Travel-Associated Severe Malaria Treated with Artesunate, France, 2011-2013

- Protective Antibodies against Placental Malaria and Poor Outcomes during Pregnancy, Benin

- Extensively Drug-Resistant Streptococcus pneumoniae, South Korea, 2011-2012

http://wwwnc.cdc.gov/eid/articles/issue/21/05/table-of-contents 